\title{
Flow of novel genes for R\&D continues
}

Sir-Your article "Curtain falls on gene sequencing deal" (Nature 391, 621; 1998) contains some comments misattributed to a SmithKline Beecham (SB) spokesperson that may have created an inaccurate impression of the status and progress of the SB/Human Genome Sciences (HGS) collaboration.

In particular, we do not feel that we have "exhaustively milked" the SB/HGS database, as quoted in the article. Indeed, we firmly believe that many novel genes of therapeutic interest remain to be discovered in this resource. However, SB is focusing its drug discovery efforts on targets that we have already identified, as a matter of strategic focus. We want to be clear that we are actively pursuing many targets obtained from the SmithKline Beecham/Human Genome Sciences database, and we continue to regard the collaboration as highly productive.

We hope that these comments clarify the status of SmithKline Beecham's collaboration with Human Genome Sciences, and resolve any ambiguity that may have arisen.

David C. U'Prichard

(Chairman, Research and Development) SmithKline Beecham plc,

One New Horizons Court,

Brentford, Middlesex TW8 9EP, UK
Sir-Your article contains statements that are misleading and incorrectly attributed. For example, SmithKline Beecham (SB) does not claim that the company has "exhaustively milked the database"; the situation is that, having initiated work on more than 3,000 novel human genes provided by Human Genome Sciences (HGS), its capacity to pursue additional, high quality leads for drug development is temporarily saturated. The flow of novel genes for research and development continues unabated to HGS's other partners, namely Schering Plough, Takeda, Merck KGaA and Synthelabo.

The article wrongly attributes to SB the sentiment that "the stringent terms imposed by HGS at the time" on researchers wishing to gain access to the database have become "increasingly unacceptable". The terms of the material transfer agreements (MTAs) that govern access to the data and materials were mutually agreed by all parties to the agreement - including SB - and have been accepted by more than 150 academic institutions. HGS has already established MTAs regarding more than 1,200 individual human genes and purified proteins with academic centres worldwide.

I would also disagree that HGS triggered a "vigorous debate over whether human genome should be mapped in the private or public domain". HGS is not - nor has it been - a genome mapping company as are Genset, Millennium, Sequanna, Myriad, deCode, Darwin and others. HGS isolates and sequences expressed messenger RNAs; we do not map them.

Your article also quotes selfcongratulation from public database providers on the completeness and adequacy of the publicly available data. But, if the public databases are adequate, why do pharmaceutical companies continue to pay large sums for access to private databases? The pharmaceutical giant Novartis, for example, signed an agreement for access to a private database in January this year.

Finally, you state that HGS is a less prominent player in the sequencing business "following the split from... The Institute of Genome Research (TIGR)". In fact, less than $5 \%$ of the HGS human gene sequencing data was generated through our collaboration with TIGR, and we continue to be a world leader in the isolation and characterization by partial and full-length sequence analysis of human cDNAs. William A. Haseltine

(Chairman and Chief Executive Officer)

Human Genome Sciences Inc., 9410 Key West Avenue,

Rockville, Maryland 20850, USA

e-mail:william_haseltine@hgsi.com

\section{New Zealand science}

Sir-Your article dealing with the outcome of New Zealand's 1992 structural reforms of science administration was of considerable interest (Nature 391, 426-427; 1998). It contained several points, however, that are likely to contribute to a misreading of the New Zealand situation.

For example, in contrast to the impression given by statements in your article (and the subsequent correction to one of the figures quoted), 349 new science positions have been established since the Crown Research Institutes (CRIs) were set up, whereas the number of additional support positions has risen by only 83 over this period.

Your article quotes criticism of the need for CRIs to make a profit. But such profits are reinvested in research and CRI facilities. Last year, the institutes generated after-tax profit of NZ\$29.8 million (US\$17.6 million), all of which was reinvested.

The competitive nature of project bidding under the Public Good Science Fund (PGSF) demands that CRIs are efficient managers. The establishment of profit targets is a proven administrative tool for encouraging good performance. It should be remembered that CRIs compete for PGSF funding with tertiary institutions that are not required to operate in the commercial marketplace.

Universities are having difficulty in funding equipment through their core funding streams, as well as from the 'contestable' science market. But CRIs have expanded their net asset base from NZ\$139.6 million to NZ\$246.5 million. Is there any reason why academic institutions cannot manage their own performance in a similar manner?

The article did not mention a critical difficulty with the reforms, namely that universities and other tertiary educational institutes can now access the PGSF funds that the CRIs need to survive. CRIs by contrast cannot access tertiary sector research funds.

It is this one-sided nature of the science 'market' that has led to an increase in the number of players and suggestions that there are too many people chasing too little money. Science career paths have not so far been significantly destabilized by this factor, although the possibility that they will is the main cause of concern that many scientists have about the reforms.

CRIs are tightly focused on science and research closely related to the needs of the New Zealand agricultural, forestry, fishing and manufacturing industries, as well as to international trade and environmental requirements of central government and local authorities. It is this responsiveness to community need that is a significant element in demonstrating to those who control government budget allocations that investment in research and science offers a better return to society than expenditure in many of the other areas that compete for funds from the public purse. Without such responsiveness, it is unlikely that science funding would have been maintained, let alone increased.

P. M. Hargreaves

(President)

New Zealand Association

of Crown Research Institutes (Inc.), PO Box 1578, Wellington,

New Zealand 